\title{
O DIREITO EM JOHN LOCKE
}

\author{
THE RIGHT IN JOHN LOCKE
}

Christian Lindberg Lopes do Nascimento*

\section{RESUMO:}

O presente artigo tem como objetivo analisar o tema do Direito em John Locke, à luz da caracterização feita por Norberto Bobbio na obra Era dos direitos (2004), na qual levanta a questão se poder-se-ia inserir o pensamento filosófico lockiano na denominada Era. Este texto busca compreender o conceito de Direito em Locke associado a outros, ainda que de forma secundária, tais como o de justiça, violação, magistrado e, sobretudo, propriedade. Tendo como foco o Direito e suas ramificações políticas, entendemos que Locke defende aquilo que os modernos chamam de "básico" para a existência de cada indivíduo, como a vida, a paz, a liberdade e a igualdade, ou seja, os bens materiais elementares para a sobrevivência humana. Esse arcabouço conceitual é referendado à medida que são adotados os livros do filósofo inglês, particularmente aqueles relacionados à Filosofia política e à Religião, como a Carta sobre a tolerância, Dois tratados sobre o governo e Ensaios políticos. PALAVRAS-CHAVE: Direito. Justiça. Locke. Propriedade. Violação.

\section{ABSTRACT:}

The subject-matter that this article aims to analyze is the concept of Law in John Locke, under the light of the characterization made by Norberto Bobbio in his work Age of Rights (2004) in which he raises the question whether we could insert the Lockean philosophical thought in the so- called Era. This text seeks to understand the concept of Law in Locke combined with others, even if in a secondary way, such as justice, violation, magistrate and, above all, property. Focusing on Law and its political ramifications, we understand that Locke defends what moderns call "basic" to the existence of each individual, such as life, Peace, freedom and equality, that meaning, the elemental material goods for the human survival. This conceptual framework is sustained by the adoption of a series of books of the english philosopher, particularly those related to Political Philosophy and Religion, such as the $A$ letter concerning toleration; Two treatises of Government and Political Essays.

KEY WORDS: Law. Justice. Locke. Property. Violation.

O tema dos Direitos Humanos foi sendo construído gradativamente no mundo moderno, e John Locke teve papel decisivo na sua formulação. O documento intitulado Bill of Rights é a marca capital sobre o tema nos moldes em que se entende hoje. Embora seja datado de 1689 e situado espacialmente na Inglaterra, ele tem como escopo principal a divisão dos poderes - Poder Legislativo e Poder Executivo -, além de ser o primeiro documento que

\footnotetext{
* Professor do Departamento de Filosofia da Universidade Federal de Sergipe. Doutor em Educação pela UNICAMP, graduado em Filosofia pela UFS. E-mail: christian.lindberg76@ gmail.com.
} 
formaliza os direitos individuais na história mais recente da humanidade. Isso foi possível porque o cenário pós-Revolução Gloriosa propiciou aos indivíduos não só sua libertação das garras do poder absolutista, como também sua abertura para a defesa da liberdade individual.

Por ser Locke um filósofo que teve certa influência na Revolução Gloriosa, seria possível afirmar que seu pensamento filosófico impactou o Bill of rights? Pode-se dizer que sim, já que o filósofo inglês é quem estabelece a perspectiva de que os indivíduos possuem, no estado de natureza, direitos naturais (liberdade, vida, bens materiais), cabendo ao pacto social preservar tais direitos. Além desse fator, é Locke quem desenvolve uma fundamentação teórica acerca da divisão dos poderes, conforme preconizado no documento citado acima.

Assim, a argumentação que será desenvolvida aqui tem como objetivo situar a filosofia lockiana na discussão que gira em torno do Direito e suas ramificações, mas que posteriormente vai tocar de alguma forma no que se entende hoje por Direitos Humanos. Para tanto, além de utilizar duas das principais obras de Locke - Dois tratados sobre o governo e Carta sobre a tolerância -, alguns outros pequenos textos dele, contidos na compilação intitulada Ensaios políticos servirão como fonte, além de comentadores relevantes para esta empreitada reflexiva.

No entanto, percebe-se que o conceito de Direito tem relação direta com outros, sendo um deles o de justiça, que aparece de forma esparsa nas obras de Locke. Nos Ensaios políticos, o termo aparece em momentos distintos. No primeiro, atribui-se a justiça a Deus, um ser perfeito, eterno e criador de criaturas dotadas dos meios necessários para alcançarem a felicidade, embora haja indivíduos que possam infringir a ordem divina. A justiça, portanto, é exercida por Ele, tornando-se um braço da bondade infinita, restringindo pela severidade aqueles que provocarem o mal. "Assim, não se pode supor que a justiça de Deus se estenda para além do que a infinita bondade julgar necessário para a preservação de Suas obras.” (LOCKE, 2007, p. 345). O segundo momento tem relação com a vida civil e diz respeito a não violação do direito alheio, sendo punido aquele que infringi-lo. Outra referência aparece quando Locke discorre sobre a moralidade, dissertando que, quando os homens se submetem a uma única regra e há sua violação, a justiça incide justamente em reparar o dano causado, tornando-se "o maior e mais difícil dever, o resto não será árduo" (LOCKE, 2007, p. 334). O termo justiça também aparece atrelado ao conceito de caridade. Nesse sentido, Locke começa defendendo que a justiça é feita quando uma mercadoria é vendida a um preço condizente com a localidade na qual ela está sendo comercializada. No entanto, ele ressalva que se o 
vendedor pode vender a mesma mercadoria por um preço mais baixo, deve fazê-lo igualmente, já que a justiça possui a mesma medida para todos os seres humanos.

\begin{abstract}
Uma pessoa pode avaliar à taxa que quiser o que ela possui e não cometerá transgressão contra a justiça se o vender a qualquer preço, desde que não faça nenhuma distinção entre compradores, mas transfira a este comprador o preço tão baixo quando transferiria a outro. Afirmo que ela não comete transgressão contra a justiça; o que ela pode cometer contra a caridade é outro caso. (LOCKE, 2007, p. 425).
\end{abstract}

No Dois tratados sobre o governo, Locke (2001, p. 244) expõe que "Deus não deixou um único homem a mercê de outrem de modo que este não pudesse fazê-lo morrer de fome se assim o desejasse." Complementa sua assertiva afirmando que a justiça "confere a cada homem o direito ao produto de seu esforço honesto e as legítimas aquisições se seus ancestrais são transmitidos a ele", e a injustiça acontece quando um homem submete o outro à vassalagem ou à escravidão. $\mathrm{O}$ conceito de justiça também tem relação direta com a autoridade exercida pelo legislador após o estabelecimento do contrato social, atribuindo-lhe a obrigação de "deliberar acerca do direito dos súditos por intermédio de leis promulgadas e fixas", evitando as inconveniências que perturbam a propriedade dos homens. (LOCKE, 2001, p. 507)

Em Carta sobre a tolerância o termo justiça aparece como um dos atributos da tolerância, já que ela está associada à benevolência e à caridade, temas que compõem a argumentação lockiana desenvolvida nesta obra. Locke (1973, p. 09), ao afirmar que "nenhum indivíduo deve atacar ou prejudicar de qualquer maneira a outrem nos seus bens civis porque professa outra religião ou forma de culto", defende que os direitos pertencem a cada indivíduo e são invioláveis, devendo ser preservados: “As leis tendem, quanto possível, para proteger os bens e a saúde dos súditos contra a violência e a fraude de terceiros." (LOCKE, 1978, p. 12)

A quarta menção aparece no livro IV do Ensaio sobre o entendimento humano. Após afirmar que a ideia de um Ser supremo é nítida, de que Ele é poderoso e criador de todas as coisas, Locke relaciona o conceito de justiça ao de propriedade, atribuindo à injustiça a violação dos direitos que cada indivíduo possui naturalmente, concedidos por Deus.

Ora, percebe-se que o conceito de justiça aparece como arcabouço teórico diante de situações nas quais a propriedade é violada. Se esta afirmação estiver correta, a reflexão que Locke desenvolve em torno do tema da justiça converte-se em um assunto moral, haja vista o 
fato de o filósofo inglês entender a propriedade no âmbito de sua Filosofia moral. Então, o que caracteriza o conceito lockiano de propriedade?

No estado de natureza, o homem age de acordo com a lei de natureza e extrai da natureza, por meio do trabalho, os meios necessários para a sua subsistência, adquirindo, portanto, sua propriedade. Desse modo, cada indivíduo pode usufruir dos recursos naturais até onde as suas necessidades de sobrevivência exigirem, até porque os alimentos necessários para a manutenção da vida são perecíveis, impedindo o acúmulo de grande quantidade. Por outro lado, o que não for de consumo próprio pertence aos outros, já que Deus não fez nada para que o homem estrague ou destrua.

Bobbio (1997, p. 187) atenta para o fato de que "os esforços feitos por Locke, em sua teoria do governo, é o de demonstrar que a propriedade é um direito natural no sentido específico de que ele nasce e se aperfeiçoa no estado da natureza." Continua sua interpretação afirmando que, com sua formulação sobre o conceito de propriedade, Locke deixa um legado original, mas controverso e inovador, porque torna tal conceito universal, já que a sua aquisição se dá por um processo de apropriação. Para que esta aquisição se torne possível, cada indivíduo precisa realizar um esforço físico, denominado de trabalho, tendo uma postura ativa diante da natureza, transformando em benefício próprio aquilo que Deus deu em abundância a todos. No mesmo comentário ele ainda faz uma ressalva importante.

\footnotetext{
Não se pode deixar de pensar na analogia entre o conhecimento entendido como pesquisa empírico-racional, e, portanto, como um esforço individual que deve escapar do aliciamento do dogmatismo e do conformismo, objetivo principal do Ensaio sobre a inteligência humana, e a propriedade, vista como fruto do esforço individual, não como um dom divino, gratuito, ou como expressão de potências atávicas. A rejeição da doutrina da doação divina em favor da doutrina do trabalho pessoal corre, paralelamente, à rejeição do cômodo princípio da autoridade em favor do princípio da investigação individual. (BOBBIO, 1997, p. 196).
}

Por outro lado, controverso porque o termo propriedade é utilizado por Locke em dois sentidos. O primeiro é mais amplo e está relacionado à ideia de direito em geral, ou à soma dos direitos à vida, à liberdade e aos bens materiais. Já o segundo, mais restrito, se reduz aos bens materiais, consequência direta do trabalho.

Tal situação faz com que o pensamento político do filósofo tenha sofrido diversas apreciações. Uma delas se fundamenta na tese lockiana de que o governo é constituído a partir do consentimento dos indivíduos; outra afirma que há predominância da moral sobre os indivíduos. No entanto, Macpherson (1979, p. 206) ressalva que: "Não é que todos os 
intérpretes da teoria política de Locke tenham esquecido seu conteúdo social. Alguns notáveis autores modernos deduziram [...] que toda a teoria de Locke de governo limitado e condicional foi essencialmente uma defesa da propriedade." Argumenta ainda que, sobre a teoria política lockiana, há aqueles que defendem que o liberalismo do filósofo tem um forte componente coletivista e não individualista. O comentador apresenta essa análise dos estudos do filósofo com um propósito: demonstrar que a noção de propriedade, em Locke, está associada ao direito natural que cada indivíduo tem, e que, por conseguinte, deve ser preservado após a constituição da sociedade política.

Entretanto, o mesmo Macpherson, ao analisar o texto de Locke, compreende que o homem tem direito à conservação de sua vida como também, a partir da realização do trabalho, à aquisição de bens materiais. Porém, observa que a transição da propriedade limitada - pela lei natural - torna-se ilimitada com a invenção do dinheiro. Isso decorre porque o homem, ao acumular dinheiro e estabelecer relações comerciais, deixa de ter apenas o necessário para o próprio sustento e passa a possuir mais bens materiais do que necessita. Dessa maneira, é estabelecida a fonte da desigualdade entre os indivíduos, do ponto de vista da posse de bens materiais.

Poder-se-ia, então, indagar que, no estado de natureza, a desigualdade entre os homens tem sua origem, e que, ao constituir tacitamente a sociedade política, cada indivíduo legitima tal situação? Essa questão é insustentável porque é impensável ter havido algum tipo de comércio entre os homens e até mesmo entre nações diversas antes da constituição do contrato social, em que pese Macpherson defender a existência de relações capitalistas ainda no estado de natureza. Para reforçar essa argumentação, interpreta que o consentimento, termo adotado por Locke no ato que antecipa a celebração do contrato social, tem dois níveis, a saber:

\footnotetext{
Um é o consentimento entre homens livres, iguais, racionais em estado de natureza [...] O outro nível de consentimento é a concordância de cada um em entregar todos os seus poderes à maioria; este é o consentimento que estabelece a sociedade civil. $\mathrm{O}$ primeiro consentimento é válido sem o segundo. Mas, embora as instituições de prioridade que são estabelecidas no estado de natureza pelo primeiro tipo de consentimento sejam moralmente válidas, elas são, na prática, difíceis de se fazer cumprir no estado de natureza. Esta dificuldade é a principal razão que Locke encontra para que os homens se voltem para o segundo nível de consentimento, entrando para a sociedade civil. (MACPHERSON, 1979, p. 222).
}

Esse comentador reforça a acepção lockiana que afirma que é para garantir a propriedade que a sociedade civil é instituída. Associado ao conceito de propriedade está o de 
trabalho, que o próprio Macpherson atribui como fonte da propriedade e fundamental para a compreensão do pensamento político do filósofo. Conclui sua argumentação dizendo que a grande relevância de Locke foi definir a propriedade como algo natural ao homem, estabelecendo uma base moral para o capitalismo.

Em sentido contrário, compreende-se que Locke atribui valor moral ao conceito de propriedade quando afirma que, no estado de natureza, o homem é regido pela lei de natureza e realiza suas ações visando à felicidade. Essa observação tem validade também quando há a passagem para a sociedade política, porque é para a manutenção da propriedade que o contrato social é estabelecido, como o próprio afirma: "Deus, que deu o mundo aos homens em comum, deu-lhes também a razão, a fim de que dela fizessem uso para maior benefício e conveniência da vida. A Terra, e tudo que há nela, é dada aos homens para o sustento e o conforto de sua existência" (LOCKE, 2001, p. 406).

Edgar Jorge Filho reforça esse tipo de análise, chegando a esta conclusão ao investigar a extensão e limites de tal conceito, a partir da seguinte questão: "até que ponto é legítimo nos apropriarmos dos produtos espontâneos da natureza, ou da terra mesma?” (JORGE FILHO, 1992, p. 80). Assim, destaca quatro respostas: 1) Somente o trabalho é o legítimo instrumento para a aquisição da propriedade; 2) A apropriação não deve ser privilegiada entre os indivíduos; 3) O limite deve ser a materialização de acordo com a utilidade de cada um, ou seja, as necessidades de subsistência; 4) Quando toda a Terra estiver ocupada, o seu acúmulo está condicionado à garantia de que os demais membros tenham a sua própria terra. Esse comentador afirma que, embora haja um crescimento populacional, sem o proporcional crescimento das fontes naturais, há o limite natural das reservas em comum, o que, com o cumprimento da lei de natureza, faz com que os indivíduos se apropriem corretamente dos recursos da natureza. Entretanto, ele faz uma advertência:

Quando alguém se apropria do máximo possível, deixa, portanto, o mínimo possível para os demais. Em outros termos, a maximização da propriedade do indivíduo, ou o seu enriquecimento ${ }^{1}$, causa fatalmente o empobrecimento dos demais. Seria absurda a obrigação de os homens enriquecerem simultaneamente; não poderia jamais constituir a lei fundamental de natureza. (JORGE FILHO, 1992, p. 116).

\footnotetext{
${ }^{1} \mathrm{O}$ enriquecimento é entendido aqui como acúmulo de bens materiais, ou maximização do luxo (JORGE FILHO, 1992, p. 117).
} 
Compreende-se, deste modo, que a lei de natureza torna-se o guia para a aquisição de bens materiais, ou seja, de propriedade. Além disso, o conceito de propriedade, em Locke, antecede a formação da própria sociedade política e de um corpo jurídico institucionalizado, o Estado. Por isso, a aquisição da propriedade, por parte de cada homem, deve ser legislada pela moral, seja no estado de natureza ou após a constituição da sociedade contratual.

No entanto, há duas ameaças à propriedade: a invenção do dinheiro e a cobiça humana. Sobre o dinheiro, Locke identifica que a vontade de possuir mais tem como consequência o seu acúmulo. Os críticos de Locke, a exemplo de Macpherson, acusam-no de incoerente, já que condicionara o limite da propriedade à lei de natureza, mas, ao mesmo tempo, a torna ilimitada com a criação do dinheiro. A cobiça, por outro lado, é a vontade de se apropriar, de forma exagerada, de terras e alimentos, motivada pelo simples desejo de obter o luxo, o que é incompatível com a lei de natureza.

Nas duas situações tem-se a violação da propriedade, ultrapassando o limite moral que a lei de natureza estabelece a cada indivíduo, provocando, consequentemente, a violência, a fraude e a extorsão. Configura-se, desse modo, o que Locke denomina de estado de guerra, designado por ele como:

\footnotetext{
O estado de guerra é um estado de inimizade e destruição; portanto, aquele que declara, por palavra ou ação, um desígnio firme e sereno, e não apaixonado ou intempestivo, contra a vida de outrem, coloca-se em estado de guerra com aquele contra quem declarou tal intenção e, assim, expõe sua própria vida ao poder dos outros, para ser tirada por aquele ou por qualquer um que a ele se junte em sua defesa ou adira a seu embate. (LOCKE, 2001, p. 395).
}

Para não incorrer no risco de o estado de guerra ser perene, os seres humanos, no usufruto de sua liberdade, estabelecem, via consentimento, o contrato social, que visa preservar os direitos naturais que estão sob risco por conta das indevidas investidas que conduzem as relações sociais ao estado de guerra. É para preservar a propriedade que a sociedade contratual é estabelecida, termo utilizado pelo filósofo inglês de duas formas: no sentido restrito, diz respeito aos bens materiais, que são apropriados por cada indivíduo por meio do trabalho; no sentido amplo, propriedade engloba não só os bens materiais, mas também a liberdade, a vida e a paz.

Adicionam-se dois direitos aos naturais: o que diz que todos os indivíduos são iguais e o de crença religiosa. O primeiro é fundamentado no Ensaio sobre o entendimento humano, quando Locke afirma que o conhecimento não é inato e que a mente humana equipara-se a 
uma folha de papel em branco, sem nada preenchido. Já o direito à crença religiosa é defendido por Locke, de forma mais enfática, na Carta sobre a tolerância, e tem como intuito promover a paz e preservar a vida. Para tanto, ele desenvolve uma argumentação que tem como alvo a separação entre vida civil e religiosa. A primeira diz respeito ao interesse público, cabendo ao contrato social regulamentá-la, e a segunda diz respeito à vida privada, deixando a cada um a opção de abraçar a religião que lhe convier².

Em resumo, o conceito de direito de Locke tem relação direta com o de propriedade, ou seja, cada indivíduo possui direitos inerentes, a saber: os bens materiais, a vida, a liberdade, a igualdade e a crença religiosa. São esses direitos que a cobiça, a invenção do dinheiro ou a transgressão da lei de natureza põem em risco. De igual modo, a justiça, conforme mencionado, aplica-se diante de situações em que a violação dos direitos acontece.

Embora o estado de natureza seja hipotético, o contratualismo lockiano o tem como referência para estabelecer algumas conexões. Nesse sentido, a reflexão que Locke desenvolve em torno do conceito de propriedade é fundamental, visto que é aqui que o conceito de direito defendido por ele encontra respaldo teórico. Desse modo, o contrato social é estabelecido para resguardar os indivíduos dos inconvenientes que porventura aconteçam no estado de natureza por meio do consentimento dos integrantes que compactuam determinado acordo, já que a condição humana pré-contratual designa direitos naturais a cada indivíduo.

Sendo todos os homens, como já foi dito, naturalmente livres, iguais e independentes, ninguém pode ser privado dessa condição nem colocado sob o poder político de outrem sem o seu consentimento. A única maneira pela qual uma pessoa qualquer pode abdicar de sua liberdade natural e revestir-se dos elos da sociedade civil é concordando com outros homens em juntar-se e unir-se em uma comunidade, para viverem confortável, segura e pacificamente uns com os outros, num gozo seguro de suas propriedades e com maior segurança contra aqueles que dela não fazem parte. (LOCKE, 2001, p. 468).

Se o contrato social é constituído para preservar os direitos inerentes a cada indivíduo, a sua violação é passível de punição. Em um texto intitulado Obrigatoriedade das leis penais, material que faz parte dos Ensaios políticos, Locke (2007, p. 293) identifica que "todas as leis humanas são penais, pois, quando a punição não está expressa, deve ser proporcionada, pelo juiz, à consequência e às circunstâncias da falta." Antes, afirma que as leis civis só existem para punir os infratores das leis divinas, que são espelhadas na lei de natureza, por serem elas

\footnotetext{
${ }^{2}$ Sobre este tema, ver Santos (2008).
} 
as garantidoras dos direitos naturais, ou seja, a propriedade. É o que Yves Michaud interpreta como um continuum, ou seja, segundo ele, há quatro tipos de leis no pensamento jusnaturalista lockiano, que agem em cada indivíduo:

\begin{abstract}
Locke distingue várias espécies de leis, que formam um continuum que governa todos os aspectos da vida humana. a) A lei divina ou moral, instituída por Deus, é conhecida pela luz natural da razão ou pela Revelação. As coisas que caem sob ela são absolutamente boas ou absolutamente más; b) A lei humana é instituída por quem quer que detenha o poder sobre os outros. Ela rege as coisas indiferentes do ponto de vista da lei divina e visa o bem-estar (welfare) da comunidade política (commonwealth); c) A lei da caridade é uma limitação que nós impomos, em nossos atos, ditada pelo cuidado de não escandalizar outrem; d) A lei monástica ou privada é aquela que nós nos impomos mesmos quando assumimos obrigações ou fazemos contratos. (MICHAUD, 1991, p. 20).
\end{abstract}

Essa divisão é esboçada quando o filósofo inglês escreve os Ensaios sobre a lei de natureza em cujo texto tem por objetivo constituir o arcabouço filosófico que comprove a extensão da lei divina na lei civil, sendo a lei de natureza aquela que tem a função de regular o convívio social do ponto de vista da moral.

Locke estabelece que as leis civis não devem estabelecer novas obrigações à consciência a não ser tornar os transgressores passíveis de punição nesta vida e não na extramundana. $\mathrm{O}$ filósofo inglês considera também que os atributos civis e divinos não são distintos devido ao fato de a lei civil ter sido constituída, via contrato social, para punir os transgressores da lei de natureza, preservando, portanto, os direitos individuais. Contudo, a lei divina intervém na vida dos indivíduos em assuntos indiferentes à sua própria natureza, até porque o Evangelho, como defende Locke (2007, p. 292), não altera minimamente os negócios civis.

Ora, considerando estes termos, o magistrado civil, compreendido como aquele dotado de legitimação para julgar os inconvenientes na sociedade política de forma imparcial, preservando os direitos, converte-se na única autoridade responsável pela punição dos infratores, agindo sempre no sentido de preservar os termos estabelecidos pelo contrato social. Assim, "fica claro que, quando se cria qualquer lei junto com uma punição, isto é, suporta-se tranquilamente a punição sem outra obediência, o governo pode ser perturbado ou colocado em perigo" (LOCKE, 2007, p. 293).

Mark Goldie identifica que Locke assume uma postura conservadora por não fazer nenhuma referência ao direito de resistência, como versa em Dois tratados sobre o governo (LOCKE, 2001), no texto "Obrigatoriedade das leis penais". No entanto, destaca que as leis 
civis têm um caráter eminentemente regulatório e que elas devem estabelecer a preservação mútua e a paz, atribuição também designada pela lei divina, ou seja, os dois tipos de leis são utilizados como justificativa para a preservação dos direitos naturais após a passagem para a sociedade política por meio do contrato social.

Talvez isso explique porque Locke estabelece, nos Ensaios políticos, que os homens são membros de uma sociedade duplicada, marcada por um duplo interesse, a saber: "a deste mundo e a do outro; e daí surgem as duas seguintes sociedades, a saber, a religiosa e a civil." (LOCKE, 2007, p. 267). No caso da sociedade civil ou política, o filósofo inglês designa algumas de suas atribuições: as leis são constituídas para garantir a felicidade civil, conservar a própria sociedade ou o governo e preservar a fruição daquilo que o mundo proporciona, a exemplo dos direitos. Consequentemente, a função do magistrado civil é utilizar a espada quando houver infrações, empregando, portanto, a força ou a punição como meio para que as leis sejam obedecidas. Já as leis religiosas são imutáveis, concebidas para a glória e felicidade em outro mundo; assim, as punições por elas designadas não são aplicadas no mundo temporal $^{3}$.

Tida como uma das principais obras de Locke, Carta sobre a tolerância tem como fio condutor a discussão em torno da tolerância religiosa. Durante a argumentação expressa no livro, ele distingue sociedade civil e religiosa. Antes, contudo, afirma que "a tolerância para os defensores de opiniões opostas acerca de temas religiosos está tão de acordo com o Evangelho e com a razão que parece monstruoso que os homens sejam cegos diante de uma luz tão clara.” (LOCKE, 1978, p. 04), e é enfático quando diferencia os assuntos mundanos dos extramundanos: "Quem mistura o céu e a terra, coisas tão remotas e opostas, confunde essas duas sociedades, as quais em sua origem, objetivo e substancialmente são por completo diversas." (LOCKE, 1978, p. 10)

Locke (1978, p. 10) afirma ainda que o magistrado deve agir com o peso dos argumentos racionais, acompanhado de humanidade e benevolência, e não cuidar das almas. De igual modo, não deve estabelecer leis que revelem o caminho para o céu, mesmo quando for adepto de uma crença religiosa. Consequentemente, ele não deve proibir que ritos religiosos distintos do que professa sejam utilizados por outras Igrejas. Em suma, Locke atribui ao magistrado as seguintes funções:

\footnotetext{
${ }^{3}$ Sobre a relação entre economia e tolerância, ver Santos (2013).
} 
É dever do magistrado civil, determinando imparcialmente leis uniformes, preservar e assegurar para o povo em geral e para cada súdito em particular a posse justa dessas coisas que pertencem a esta vida. Se alguém pretende violar tais leis, opondose à justiça e ao direito, tal pretensão deve ser reprimida pelo medo do castigo, que consiste na privação ou diminuição dos bens civis que de outro modo podia e devia usufruir. Mas vendo que ninguém se permite voluntariamente ser despojado de qualquer parte de seus bens, muito menos de sua liberdade ou de sua vida, o magistrado reveste-se de força, ou seja, com toda a força de seus súditos, a fim de punir os que infringiram quaisquer direitos de outros homens. (LOCKE, 1978, p. 5).

É na obra Dois tratados sobre o governo que o tema do magistrado é revestido, única e exclusivamente, de um caráter político. Após afirmar que ele deve ser imparcial, probo, conhecido e com autoridade para solucionar as diferenças, tendo como parâmetro o contrato social, Locke admite que o poder do magistrado é limitado ao bem público da sociedade, que é alicerçado nas leis de natureza e sua extensão, ou seja, a lei civil. Assim, o seu poder não pode ser regido por decretos arbitrários, muito menos depender do seu bel-prazer. De igual modo, o magistrado não pode transferir o poder que lhe foi concebido para as mãos de terceiros, muito menos deve se apropriar da propriedade de outrem sem o consentimento deste.

Contudo, Locke identifica que o poder do magistrado pode perder suas prerrogativas legais quando: 1) O legislativo é alterado, dissolvido ou interrompido; 2) Age contrariamente ao encargo que lhe foi confiado, tentando, por exemplo, violar os termos que estabeleceram o contrato social ou a propriedade; 3) Empregar a força e as demais prerrogativas consentidas pela sociedade a ele para corromper os demais magistrados em benefício próprio. Para estas situações é legítimo o povo dissolver o poder do magistrado e reestabelecer outro contrato social. Em suma:

\begin{abstract}
Quando a sociedade colocou o legislativo em qualquer assembleia de homens para continuar neles e em seus sucessores, com instruções e autoridade para indicar tais sucessores, o legislativo não pode jamais retornar ao povo enquanto durar esse governo, pois o povo, tendo conferido ao legislativo um poder de continuar para sempre, cedeu-lhe o seu poder político e não pode retomá-lo. Mas, se fixou limites para a duração desse legislativo e tornou apenas temporário esse poder supremo em qualquer pessoa ou assembleia, ou então, se por faltas por parte dos que detêm a autoridade, o direito a esse poder é perdido, com a perda do direito dos governantes a esse poder ou ao terminar o prazo estabelecido, retorna esse poder à sociedade, e o povo tem o direito de agir como supremo e continuar o legislativo em si mesmo, ou instituir uma nova forma, ou ainda, sob a forma antiga, colocá-lo em novas mãos, conforme julgar adequado. (LOCKE, 2001, p. 601).
\end{abstract}


Esses traços caracterizam o que Locke identifica como dissolução do governo, situação na qual os indivíduos que consentiram o contrato social têm legitimidade para dissolvê-lo. Isto ocorre, como se vê, quando o magistrado age contrariamente aos ditames listados na lei civil, pondo em risco os direitos inerentes de cada indivíduo. Assim, a dissolução do governo é a forma encontrada por Locke para garantir a justiça e punir a violação dos magistrados infratores.

Como se vê, Locke identifica o magistrado civil, termo que aparece nas reflexões que ele desenvolveu em torno da política e da religião, como aquele dotado de legitimação para preservar os direitos individuais, que age de forma imparcial e não de acordo com seu arbítrio, cumprindo o acordo consentido pelos integrantes da sociedade política no ato que a constituiu. De igual modo, o magistrado tem o dever de garantir as propriedades de cada indivíduo, agindo de acordo com a justiça quando for necessário, ou seja, quando há o risco de violação por parte de outrem.

O tema do Direito é repleto de nuances em John Locke. Partindo-se do que ele denomina de justiça - que significa a intervenção humana aplicada quando existe a violação visando garantir a propriedade -, observa-se que o conceito de direito tem relação direta com o de propriedade, seja no sentido restrito - bens materiais -, ou no amplo - bens materiais, vida, paz, liberdade, igualdade. Essa condição se manifesta no estado de natureza e serve como alicerce para a constituição da sociedade política, solução encontrada por Locke para preservar os direitos individuais e que é instituída por consentimento via celebração de um contrato social, desde que a cobiça e o acúmulo não sejam manifestados na ação de um único indivíduo, o que os poria em estado de guerra. Por outro lado, o direito à liberdade de crença, tema discutido pelo filósofo inglês na Carta sobre a tolerância, é compreendido como um direito civil, o que requer a sua inclusão na lista dos direitos celebrados no contrato social.

O consentimento, que instituiu a sociedade política, ao mesmo tempo que serve para fundamentar a preservação dos direitos individuais, estabelece a constituição de um juiz imparcial e que tenha a legitimidade suficiente para intervir nos inconvenientes que porventura aconteçam, desde que ele não transgrida as leis civis. Assim, a figura do magistrado é fundamental para preservar os direitos individuais, requerendo dele habilidades 
inerentes ao cargo, como, por exemplo, respeitar as prerrogativas próprias da função ou não intervir em assuntos de cunho religioso, exceto nas "coisas indiferentes". 4

Enfim, a discussão que gira em torno do tema do Direito em Locke é instigante à medida que está associado aos conceitos de propriedade, justiça, direito natural/civil e magistrado. Ele protagoniza uma tradição filosófica que repercutiu na Modernidade e que ficou conhecida como Era dos direitos, com ecos até os dias atuais. Numa época em que esses direitos estão sendo revistos e subtraídos, voltar ao pensamento de Locke é uma obrigação moral de primeira grandeza.

\section{REFERÊNCIAS}

BOBBIO, Norberto. Locke e o direito natural. Tradução Sérgio Bact. 2. ed. Brasília: EdUnB, 1997.

BOBBIO, Norberto. A era dos direitos. Tradução Carlos Nelson Coutinho. Rio de Janeiro: Elsevier, 2004.

DIDEROT; D’ALEMBERT. Verbetes políticos da Enciclopédia. Tradução Maria das Graças Souza. São Paulo: Discurso Editorial; EdUNESP, 2006.

JORGE FILHO, Edgar. Jorge. Moral e história em John Locke. São Paulo: Loyola, 1992.

LOCKE, John. Carta sobre a tolerância. Tradução Anoar Aiex e E. Jacy Monteiro. São Paulo: Abril Cultural, 1973.

LOCKE, John. Dois tratados sobre o governo. Tradução Júlio Fischer. São Paulo: Martins Fontes, 2001.

LOCKE, John. Ensaio sobre o entendimento humano. Tradução Pedro Paulo Garrido Pimenta. São Paulo: Martins Fontes, 2012.

LOCKE, John. Ensaios políticos. Organização de Mark Goldie. Tradução Eunice Ostrensky. São Paulo: Martins Fontes, 2007.

MACPHERSON, Crawford Brough. A teoria política do individualismo possessivo de Hobbes até Locke. Tradução de Nelson Dantas. Rio de Janeiro: Paz e Terra, 1979.

MICHAUD, Yves. Locke. Rio de Janeiro: Paz e Terra, 1991.

PINSKY, Carla Bassanezi; PINSKY, Jaime (Org.). História da cidadania. São Paulo: Contexto, 2003.

\footnotetext{
${ }^{4}$ Sobre este tema, ver Viana (2017).
} 
SANTOS, Antônio Carlos dos. Locke. In: PECORARO, R.: Os filósofos clássicos da filosofia. v. 1. Rio de Janeiro: Vozes, 2008.

SANTOS, Antônio Carlos dos. John Locke e o argumento da economia para a tolerância. Revista TRANS/FORM/AÇÃO, Marília, v.36, n.01, p. 09-24, 2013. Disponível em: < http://www.scielo.br/pdf/trans/v36n1/02.pdf >. Acesso em: 23/08/2017.

VIANA, Mykael. O conceito de coisas indiferentes em John Locke. 2017. Dissertação (Mestrado em Filosofia). Programa de Pós-graduação em Filosofia, Universidade Federal de Sergipe, São Cristóvão, 2017.

VOLTAIRE. Dicionário filosófico. Tradução Marilena Chauí. 2.ed. São Paulo: Abril Cultural, 1978. 